\title{
Prevalence of high risk obstructive sleep apnoea by Berlin questionnaire in patients with hypertension: study from a tertiary care hospital
}

\author{
Ozaifa Kareem ${ }^{1}$, Masood Tanvir ${ }^{2}$ and G. N. Bader ${ }^{1 *}$ (D)
}

\begin{abstract}
Background: Obstructive Sleep Apnoea (OSA), a condition characterized by a complete or partial cessation of airflow during sleep, can cause various cardiovascular disorders including hypertension. The aim of the study was to determine the prevalence of OSA in patients with hypertension.

Methods: A cross-sectional prospective cohort study of 504 patients with hypertension was undertaken at a tertiary care hospital of India for a period of 6 months. OSA was evaluated using the Berlin questionnaire while the daytime sleepiness was determined using Epworth Sleepiness Scale. Data analysis was done using SPSS v. 20.

Results: High risk of OSA was identified in 120 (23.8\%) patients and the prevalence of sleepiness (Epworth Sleepiness score $>16)$ was found to be $32.5 \%(95 \% \mathrm{Cl}, p<0.001)$ in these patients. The mean neck circumference, waist circumference and waist-to-hip ratio for high-risk OSA group were $37.41 \pm 3.396 \mathrm{~cm}, 105.90 \pm 11.28 \mathrm{~cm}$ and $1.01 \pm 0.065$ respectively while for the low-risk group, these parameters were $35.45 \pm 2.652 \mathrm{~cm}, 98.75 \pm 10.87 \mathrm{~cm}$ and $0.99 \pm 0.080$ respectively $(95 \% \mathrm{Cl}, p<0.001$ ). The mean blood pressure (BP) $\geq 133.52 / 84.37 \mathrm{mmHg}$ was recorded in patients with a high risk of OSA $(95 \% \mathrm{Cl}, P<0.05)$, and resistant hypertension (3.3\%) was significantly associated with the risk of OSA $(95 \% \mathrm{Cl}, P<0.05)$.

Conclusion: In the tertiary health care setting, the prevalence of high-risk of OSA in patients with hypertension is high. Screening for OSA should be a part of the hypertensive medical investigation and patients may benefit from a proper evaluation of OSA.
\end{abstract}

Keywords: Obstructive sleep apnoea, Hypertension, Berlin questionnaire, Epworth sleepiness scale

\section{Background}

Obstructive Sleep Apnoea (OSA) is a sleep-related breathing disorder that involves complete or partial cessations in airflow due to the collapse of the upper airway, despite an ongoing effort to breathe (Guilleminault and Abad 2004). The obstruction of the upper airway occurs because of the inadequate motor tone of the tongue and/or airway dilator muscles, (Park et al. 2011)

\footnotetext{
* Correspondence: gnbader@kashmiruniversity.ac.in

${ }^{1}$ Department of Pharmaceutical Sciences, University of Kashmir, Hazratbal,

Srinagar, J\&K 190006, India

Full list of author information is available at the end of the article
}

that is associated with fragmented sleep pattern, arousals from sleep and fall in oxygen saturation (Pien et al. 2015). Nocturnal oxygen desaturations cause sympathetic surges conducive to the development of acute cardiovascular events (i.e., stroke, myocardial infarction, and nocturnal sudden death) and chronic conditions such as systemic hypertension, coronary artery disease, and heart failure (Bradley and Floras 2003; Leung and Bradley 2001; Peppard et al. 2000). Hypertension is an important public health challenge worldwide because of its high frequency and concomitant risk of cardiovascular (CV)/cerebrovascular morbidity and mortality (Kearney et al. 2005; Lawes et al. 2008).

(c) The Author(s). 2020 Open Access This article is licensed under a Creative Commons Attribution 4.0 International License, which permits use, sharing, adaptation, distribution and reproduction in any medium or format, as long as you give appropriate credit to the original author(s) and the source, provide a link to the Creative Commons licence, and indicate if changes were made. The images or other third party material in this article are included in the article's Creative Commons licence, unless indicated otherwise in a credit line to the material. If material is not included in the article's Creative Commons licence and your intended use is not permitted by statutory regulation or exceeds the permitted use, you will need to obtain permission directly from the copyright holder. To view a copy of this licence, visit http://creativecommons.org/licenses/by/4.0/. 
It is estimated to cause 7.5 million deaths that are $12.8 \%$ of the total number of deaths worldwide (Global Health Observatory 2018).

Globally, various epidemiological studies report that about $30 \%$ of patients with OSA have hypertension, (Bouloukaki et al. 2018; Lavie et al. 2000; Marin et al. 2012; Mubarik et al. 2017) while in patients with resistant hypertension the prevalence of OSA is reported to be $80 \%$ (Min et al. 2015; Muxfeldt et al. 2014).

Epidemiological studies from Asia have shown that the prevalence of OSA in patients with hypertension varies from 14 to $75 \%$ (Ip et al. 1999; Pensuksan et al. 2014; Shirani et al. 2016; Wali et al. 2017). A number of studies from India have garnered data regarding the overall prevalence of OSA in general population (Sharma et al. 2006; Reddy et al. 2009; Sharma et al., 2010; Udwadia et al. 2004). However, there is insufficient data to determine the prevalence of OSA in patients with hypertension. This lack of epidemiological aspects confirming relation if any, of hypertension with OSA has remained an unmet research need. The current study investigates the prevalence of OSA in confirmed hypertensive cases and correlates the severity of hypertension and OSA in terms of Berlin and Epworth scores.

\section{Methods}

This cross-sectional study was conducted at the Department of General Medicine of a tertiary care hospital of India. The participants were prospectively selected for a period of 6 months. Patients 18 years and older, of both sexes, who came for consultation/treatment at the Department of General Medicine, with a known case of hypertension were enrolled for the study and a wellinformed consent was taken from all the patients before enrollment in the study. Hypertension was categorized, as stage $1(140-159 / 90-99 \mathrm{mmHg})$ and stage $2(\geq 160 /$ $100 \mathrm{mmHg}$ ) based on the guidelines by the American Heart Association on Prevention, Detection, Evaluation, and Treatment of High Blood Pressure (Williams et al. 2018). Resistant Hypertension was defined as the failure to control clinic BP levels, despite the use of $\geq 3$ antihypertensive drugs in optimal dosages, ideally including a diuretic, or achieving it with $\geq 4$ drugs (Calhoun et al. 2008), while uncontrolled hypertension was defined as an office BP $\geq 140 / 90 \mathrm{mmHg}$ at the day of consultation (James et al. 2014). All patients, who consented to participate, were recruited by one attending physician. The patients were asked to complete a standardized questionnaire surveying the information regarding demographics and lifestyle factors (Table 1). In addition to this, the Berlin questionnaire (Tan et al. 2017) was used to determine the risk of developing OSA, dividing the patients into high and low-risk categories (Netzer et al. 1999). The Epworth sleepiness scale (ESS) was used to
Table 1 Baseline demographic and clinical characteristics of the study patients

\begin{tabular}{|c|c|c|}
\hline Variable & $\begin{array}{l}\text { Low Risk } \\
\text { Subjects } \\
N=384\end{array}$ & $\begin{array}{l}\text { High Risk } \\
\text { Subjects } \\
N=120\end{array}$ \\
\hline Age - yrs & $56.5 \pm 12.4$ & $53.4 \pm 9.02$ \\
\hline Height - m & $1.60 \pm 0.092$ & $1.61 \pm 0.099$ \\
\hline Body Weight - kg & $65.19 \pm 11.085$ & $73.63 \pm 14.31$ \\
\hline$B M I^{a}-k g / m^{2}$ & $25.5 \pm 4.57$ & $28.75 \pm 5.42$ \\
\hline Neck Circumference - cm & $35.45 \pm 2.652$ & $37.41 \pm 3.396$ \\
\hline Waist Circumference $-\mathrm{cm}$ & $98.75 \pm 10.87$ & $105.90 \pm 11.28$ \\
\hline Hip Circumference - cm & $98.85 \pm 8.59$ & $104.25 \pm 9.99$ \\
\hline Waist to Hip Ratio & $0.99 \pm 0.080$ & $1.01 \pm 0.065$ \\
\hline \multicolumn{3}{|l|}{ Epworth Sleepiness Score } \\
\hline Lower Normal Daytime Sleepiness & $3.45 \pm 1.091$ & $3.375 \pm 1.025$ \\
\hline Higher Normal Daytime Sleepiness & $7.73 \pm 1.330$ & $7.94 \pm 1.279$ \\
\hline Mild Excessive Daytime Sleepiness & $11.32 \pm 0.476$ & $11.77 \pm 0.437$ \\
\hline $\begin{array}{l}\text { Moderate Excessive Daytime } \\
\text { Sleepiness }\end{array}$ & $13.75 \pm 0.808$ & $13.85 \pm 0.834$ \\
\hline Severe Excessive Daytime Sleepiness & $17.45 \pm 2.018$ & $18 \pm 1.805$ \\
\hline Total Therapy Used & $1.27 \pm 0.497$ & $1.44 \pm 0.631$ \\
\hline \multicolumn{3}{|l|}{ Co-morbidities (No.) } \\
\hline Diabetes & 84 & 33 \\
\hline Sub-Clinical Hypothyroidism & 31 & 17 \\
\hline Dyslipidemia & 12 & 8 \\
\hline Obesity & 12 & 8 \\
\hline NAFLD & 6 & 6 \\
\hline Others & 140 & 26 \\
\hline
\end{tabular}

Data is reported as number (percentage) or mean \pm standard deviation

${ }^{\mathrm{a}} B M I$ Indicates body mass index

evaluate sleep propensity in patients. The scale covers the whole range of sleep propensities, from the highest to the lowest. ESS classified subjects into five groups based on the score: 0-5, Lower Normal Daytime Sleepiness; 6-10, Higher Normal Daytime Sleepiness; 11-12, Mild Excessive Daytime Sleepiness; 13-15, Moderate Excessive Daytime Sleepiness; 16-24, Severe Excessive Daytime Sleepiness (Johns 1991). After the completion of questionnaires, measurement of BP, height, weight, waist circumference (WC), neck circumference (NC), and hip circumference, were taken. BP measurement was recorded using a mercury sphygmomanometer (Speider \& Keller, Jungingen, Germany) and/or oscillometric devices, according to the recommendations of the American Heart Association Council on High Blood Pressure Research (Muntner et al. 2019). Height and weight measurements were obtained to calculate BMI and to categorize underweight $\left(\mathrm{BMI}<18 \mathrm{~kg} / \mathrm{m}^{2}\right)$, normal weight $\left(18.5-24.9 \mathrm{~kg} / \mathrm{m}^{2}\right)$, overweight $(25-$ $\left.29.9 \mathrm{~kg} / \mathrm{m}^{2}\right)$, class 1 obesity $\left(30-34.9 \mathrm{~kg} / \mathrm{m}^{2}\right)$, class 2 
obesity (35-39.9 kg/m²), and class 3- extreme obesity $\left(\geq 40 \mathrm{~kg} / \mathrm{m}^{2}\right)$ (World Health Organization 2016). The normal cut-off value for NC was taken as $35.5 \mathrm{~cm}$ for men and $32 \mathrm{~cm}$ for women (Fink, 2012). WC was defined using the new International Diabetes Federation criteria for Asians: WC $\geq 90 \mathrm{~cm}$ for men and $\geq 80 \mathrm{~cm}$ for women (International Diabetes Federation 2019). The ethical clearance for the study was obtained from the institutional review board of Government Medical College/SMHS under the investigation vide number: 108/ETH/GMC/ICM Dated 28/10/2017. A flow diagram depicting the number of subjects recruited at each step is shown in Fig. 1.

A sample size of 504 patients was calculated based on the estimated prevalence of OSA of $40 \%$ (Senaratna et al. 2017) among case-patients, with a power of $90 \%$ and an $\alpha$ error of $5 \%$. The statistical analysis was done using IBM SPSS (Statistical Package for the Social Sciences), V·20.0. (Armonk, NY: IBM Corp) software. Data is expressed as mean $\pm \mathrm{SD}$. The differences between means were compared using the Student $\mathrm{t}$-test. Factors associated with high risk of OSA and excessive daytime sleepiness (EDS) were identified using the $x^{2}$ test in the univariate analysis. Significant variables from the $\chi^{2}$ test were then included in the multivariate logistic regression model for the assessment of the independent effect of individual factors. A $p$-value of $<0.05$ was considered statistically significant.

\section{Results}

Over a period of 6 months, 737 subjects were surveyed, of which $504(69 \%)$ responded and completed the study. In this sample, men and women were nearly equally distributed (male 253: female 251). The mean age of the sample was $56 \pm 11$ years. On the basis of the Berlin questionnaire, the study population was divided into two groups according to patients exhibiting high risk and low-risk of OSA. High risk of OSA, as per the Berlin questionnaire, was present in $23.8 \%(n=120)$ of the population (Fig. 3) and the severe excessive daytime sleepiness, according to the Epworth Sleepiness Scale, was present in $32.5 \%(n=39)$ participants of the highrisk group. The high-risk of OSA was present in 43.3\% males and $56.7 \%$ females while low-risk was present in $52.3 \%$ males and $47.7 \%$ females $(p=0.05)$ (Table 2$)$.

The anthropometric indices, including BMI, NC, WC, were significantly higher in patients with high-risk of OSA ( $p<0.001 ; 95 \%$ CI for all comparisons). The mean BMI for the patients with high-risk of OSA was $28.75 \pm$ $5.4 \mathrm{~kg} / \mathrm{m}^{2}$ and $25.51 \pm 4.5 \mathrm{~kg} / \mathrm{m}^{2}(p<0.001 ; 95 \% \mathrm{CI})$ for the low-risk group. However, the mean WHR for the two groups was clinically insignificant. About $97 \%$ of patients in the high-risk group had abnormal WHR while only $4.7 \%$ of the low-risk group had normal WHR ( $p=$ $0.295 ; 95 \% \mathrm{CI})$. The descriptive statistical analysis of various anthropometric parameters in study patients is given in Table 2.

The mean systolic and diastolic BP measurements were significantly higher in patients with a high risk of OSA $(p<0.05$; 95\% CI) (Fig. 4). Uncontrolled hypertension was present in 50\% $(n=60)$ of patients with highrisk for OSA while $57.6 \%(n=221)$ of patients had controlled hypertension in low-risk group $(p=0.146 ; 95 \%$ CI). Resistant hypertension was present in $3.3 \%(n=4)$ subjects in high-risk OSA category while 99.5\% $(n=382)$ subjects in low-risk group had non-resistant hypertension $(p<0.05 ; 95 \% \mathrm{CI})$. The Epworth score of $>10$ was found in $62.5 \%(n=75)$ patients with high-risk for OSA and $<10$ was found in $86.1 \%(n=331)$ among low-risk group $(p<0.001 ; 95 \% \mathrm{CI})$. The patients with high-risk for OSA tended to use more medication than the lowrisk group, with $7.5 \%$ of patients in the former group using three drugs simultaneously while only $2.08 \%$ in the latter group used triple therapy $(p<0.05 ; 95 \% \mathrm{CI})$.

The most notable clinical variables in univariate analyses associated with high-risk of OSA were BP,

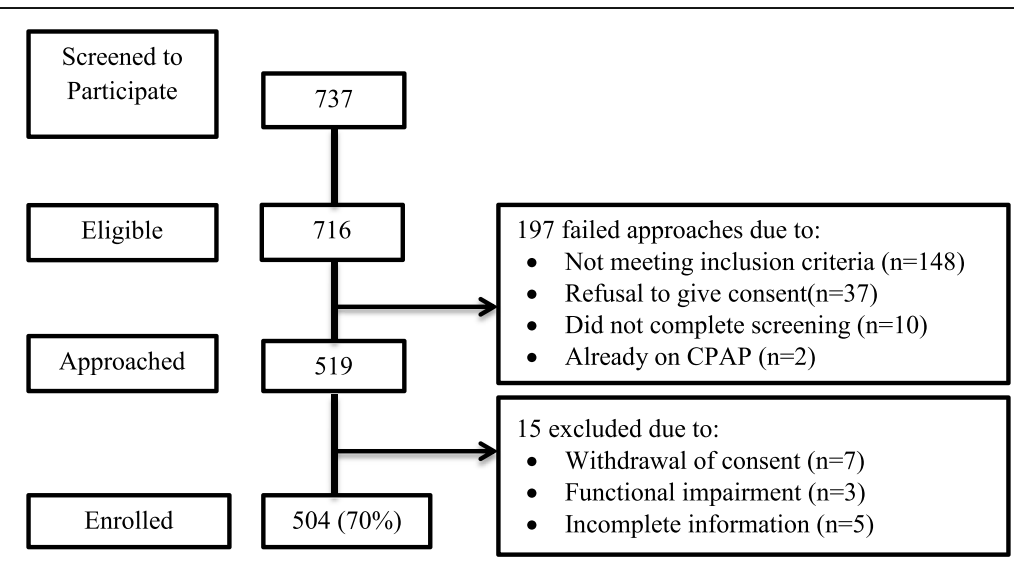

Fig. 1 Flowchart of the screened patients 
Table 2 Descriptive statistical analysis of various anthropometric parameters in study patients

\begin{tabular}{|c|c|c|c|c|c|}
\hline Parameter & & Low Risk & High Risk & Total & $P$-value \\
\hline \multicolumn{6}{|l|}{ Sex } \\
\hline \multirow[t]{2}{*}{ Male } & Count & 201 & 52 & 253 & 0.05 \\
\hline & $\%$ within Berlin category & $52.3 \%$ & $43.3 \%$ & $50.2 \%$ & \\
\hline \multirow[t]{2}{*}{ Female } & Count & 183 & 68 & 251 & \\
\hline & $\%$ within Berlin category & $47.7 \%$ & $56.7 \%$ & $49.8 \%$ & \\
\hline \multicolumn{6}{|l|}{ BMI } \\
\hline \multirow[t]{2}{*}{$<30 \mathrm{~kg} / \mathrm{m}^{2}$} & Count & 327 & 75 & 402 & 0.001 \\
\hline & $\%$ within Berlin category & $85.1 \%$ & $19.5 \%$ & $79.8 \%$ & \\
\hline \multirow[t]{2}{*}{$\geq 30 \mathrm{~kg} / \mathrm{m}^{2}$} & Count & 57 & 45 & 102 & \\
\hline & $\%$ within Berlin category & $14.8 \%$ & $37.5 \%$ & $20.2 \%$ & \\
\hline \multicolumn{6}{|c|}{ Neck Circumference ${ }^{a}$} \\
\hline \multirow[t]{2}{*}{ Normal } & Count & 134 & 14 & 148 & 0.001 \\
\hline & $\%$ within Berlin category & $34.9 \%$ & $11.7 \%$ & $29.4 \%$ & \\
\hline \multirow[t]{2}{*}{ Abnormal } & Count & 250 & 106 & 356 & \\
\hline & $\%$ within Berlin category & $65.1 \%$ & $88.3 \%$ & $70.6 \%$ & \\
\hline \multicolumn{6}{|c|}{ Waist Circumference $^{b}$} \\
\hline \multirow[t]{2}{*}{ Normal } & Count & 104 & 12 & 116 & 0.001 \\
\hline & $\%$ within Berlin category & $27.1 \%$ & $10.0 \%$ & $23.0 \%$ & \\
\hline \multirow[t]{2}{*}{ Abnormal } & Count & 280 & 108 & 388 & \\
\hline & $\%$ within Berlin category & $72.9 \%$ & $90.0 \%$ & $77.0 \%$ & \\
\hline \multicolumn{6}{|l|}{$\mathrm{WHR}^{c}$} \\
\hline \multirow[t]{2}{*}{ Normal } & Count & 18 & 3 & 21 & 0.295 \\
\hline & $\%$ within Berlin category & $4.7 \%$ & $2.5 \%$ & $4.2 \%$ & \\
\hline \multirow[t]{2}{*}{ Abnormal } & Count & 366 & 117 & 483 & \\
\hline & $\%$ within Berlin category & $95.3 \%$ & $97.5 \%$ & $95.8 \%$ & \\
\hline
\end{tabular}

${ }^{\text {a }}$ The cut-off for neck circumference of male and female were taken as 35.5 and $32 \mathrm{~cm}$ respectively

$\mathrm{b}$ The WHO standards put cut-off for waist circumference for male and female at 94 and $80 \mathrm{~cm}$ respectively

${ }^{c} \mathrm{~A}$ normal waist-to hip ratio is taken as 0.88 and 0.81 for male and female respectively

sleepiness, hypertension control-status, resistant hypertension, diabetes, and obesity. The most common comorbidities associated with hypertension were type 2 diabetes mellitus (23.2\%), subclinical hypothyroidism (9.5\%), dyslipidemia (4\%), obesity (4\%), and nonalcoholic fatty liver disease (2.4\%) (Table 1$)$. The highrisk group presented with disturbed sleep (29.2\%), high daytime somnolence (32.5\%), high fatigue/lethargy (46.7\%), and loud snoring (84.2\%) while these parameters were relatively normal in the low-risk group $(p<$ $0.001 ; 95 \% \mathrm{CI}$ ). The clinical parameters of study patients are summarized in Table 3.

\section{Discussion}

The present study is a large data set furnishing information regarding the prevalence of obstructive sleep apnoea in patients with hypertension in India. The target population was identified on the basis of physician detected hypertension and the patient data was collected by a standardized protocol on snoring, daytime sleepiness, $\mathrm{BP}$, and other features associated with OSA.

Our study demonstrates that OSA is widely prevalent in patients with hypertension. Based on the standard Berlin questionnaire, $24 \%$ of the test population was found to be at high risk for OSA (i.e., 1 in every 4 hypertensive individuals). Our study is in accordance with studies by Peppard and colleagues who identified $24-28 \%$ prevalence of OSA in hypertension (Peppard et al. 2013).

The prevalence of daytime sleepiness in this sample was $62.5 \%$ by the Epworth scale result above 10 points. This prevalence in our sample is in agreement with the prevalence identified in a previous report of patients with hypertension (Ngahane et al. 2015). In that study, the authors identified the prevalence of excessive daytime sleepiness to be $62.78 \%$ (95\% CI 58.08 to 67.47 ).

The overall mean age of the high risk for OSA respondents was $53.4 \pm 9.02$ years. The prevalence of OSA was highest between 51 and 60 years of age and this risk 
Table 3 Descriptive statistical analysis of various clinical parameters in study patients

\begin{tabular}{|c|c|c|c|c|c|}
\hline Parameter & & Low Risk & High Risk & Total & $P$-value \\
\hline \multicolumn{6}{|l|}{ Blood Pressure $(\mathrm{mm} \mathrm{Hg})$} \\
\hline Systolic & & $130.21 \pm 17.244$ & $133.52 \pm 17.503$ & & $<0.05$ \\
\hline Diastolic & & $82.69 \pm 9.531$ & $84.37 \pm 7.425$ & & \\
\hline \multicolumn{6}{|l|}{ Hypertension Control } \\
\hline \multirow[t]{2}{*}{ Controlled } & Count & 221 & 60 & 281 & 0.146 \\
\hline & $\%$ within Berlin category & $57.6 \%$ & $50.0 \%$ & $55.8 \%$ & \\
\hline \multirow[t]{2}{*}{ Uncontrolled } & Count & 163 & 60 & 223 & \\
\hline & $\%$ within Berlin category & $42.4 \%$ & $50.0 \%$ & $44.2 \%$ & \\
\hline \multicolumn{6}{|l|}{ Resistant Hypertension } \\
\hline \multirow[t]{2}{*}{ Non-Resistant hypertension } & Count & 382 & 116 & 498 & $<0.05$ \\
\hline & $\%$ within Berlin category & $99.5 \%$ & $96.7 \%$ & $98.8 \%$ & \\
\hline \multirow[t]{2}{*}{ Resistant hypertension } & Count & 2 & 4 & 6 & \\
\hline & $\%$ within Berlin category & $0.5 \%$ & $3.3 \%$ & $1.2 \%$ & \\
\hline \multicolumn{6}{|l|}{ Epworth Score } \\
\hline \multirow[t]{2}{*}{$0-5$} & Count & 205 & 16 & 221 & $<0.001$ \\
\hline & $\%$ within Berlin category & $53.4 \%$ & $13.3 \%$ & $43.8 \%$ & \\
\hline \multirow[t]{2}{*}{$6-10$} & Count & 126 & 29 & 155 & \\
\hline & $\%$ within Berlin category & $32.8 \%$ & $24.2 \%$ & $30.8 \%$ & \\
\hline \multirow[t]{2}{*}{$11-12$} & Count & 25 & 17 & 42 & \\
\hline & $\%$ within Berlin category & $6.5 \%$ & $14.2 \%$ & $8.3 \%$ & \\
\hline \multirow[t]{2}{*}{$13-15$} & Count & 17 & 19 & 36 & \\
\hline & $\%$ within Berlin category & $4.4 \%$ & $15.8 \%$ & $7.1 \%$ & \\
\hline \multirow[t]{2}{*}{$16-24$} & Count & 11 & 39 & 50 & \\
\hline & $\%$ within Berlin category & $2.9 \%$ & $32.5 \%$ & $9.9 \%$ & \\
\hline \multicolumn{6}{|l|}{ Therapy } \\
\hline \multirow[t]{2}{*}{ Off Therapy } & Count & 1 & 0 & 1 & $<0.05$ \\
\hline & $\%$ within Berlin category & $0.26 \%$ & $0.0 \%$ & $0.26 \%$ & \\
\hline \multirow[t]{2}{*}{ Monotherapy } & Count & 284 & 77 & 361 & \\
\hline & $\%$ within Berlin category & $73.9 \%$ & $64.1 \%$ & $71.6 \%$ & \\
\hline \multirow[t]{2}{*}{ Double Therapy } & Count & 91 & 34 & 125 & \\
\hline & $\%$ within Berlin category & $23.6 \%$ & $28.3 \%$ & $24.8 \%$ & \\
\hline \multirow[t]{2}{*}{ Triple Therapy } & Count & 8 & 9 & 17 & \\
\hline & $\%$ within Berlin category & 2.08 & $7.5 \%$ & $3.37 \%$ & \\
\hline
\end{tabular}

increased exponentially from $0.8 \%$ at $\leq 30$ years of age to $41.7 \%$ at $51-60$ years of age $(p<0.001)$ (Fig. 2). This finding is in agreement with the previous studies demonstrating the effect of age on OSA status (Deng et al. 2014; Ip et al. 1999).

The seventh report of the Joint National Committee on Prevention, Detection, Evaluation, and Treatment of High Blood Pressure recognizes both the independent role of OSA in the development of hypertension and OSA in association with obesity (Chobanian et al. 2003). In our study, patients with high-risk of OSA had significantly higher BMI, WC, WHR, and NC values statistically as compared to the patients with low-risk of OSA (Fig. 3). All of the anthropometric indices (NC, $\mathrm{WC}$, and BMI) were significantly correlated with the risk of OSA. These results are similar to those of previous studies. Kang et al. reported that NC [95\% CI; $p<0.001]$, WC (95\% CI; $p<0.001)$, and BMI $(95 \% \mathrm{CI} ; p<0.001)$ were significantly associated with the presence of OSA (Kang et al. 2014). Hiestand and colleagues reported that among obese subjects (BMI $\geq 30 \mathrm{~kg} / \mathrm{m}^{2}$ ), $59 \%$ of subjects were at high risk of OSA (Hiestand et al. 2006). In our study, only $37.5 \%$ of subjects were at high risk of OSA among obese patients (BMI $\left.\geq 30 \mathrm{~kg} / \mathrm{m}^{2}\right)$. 


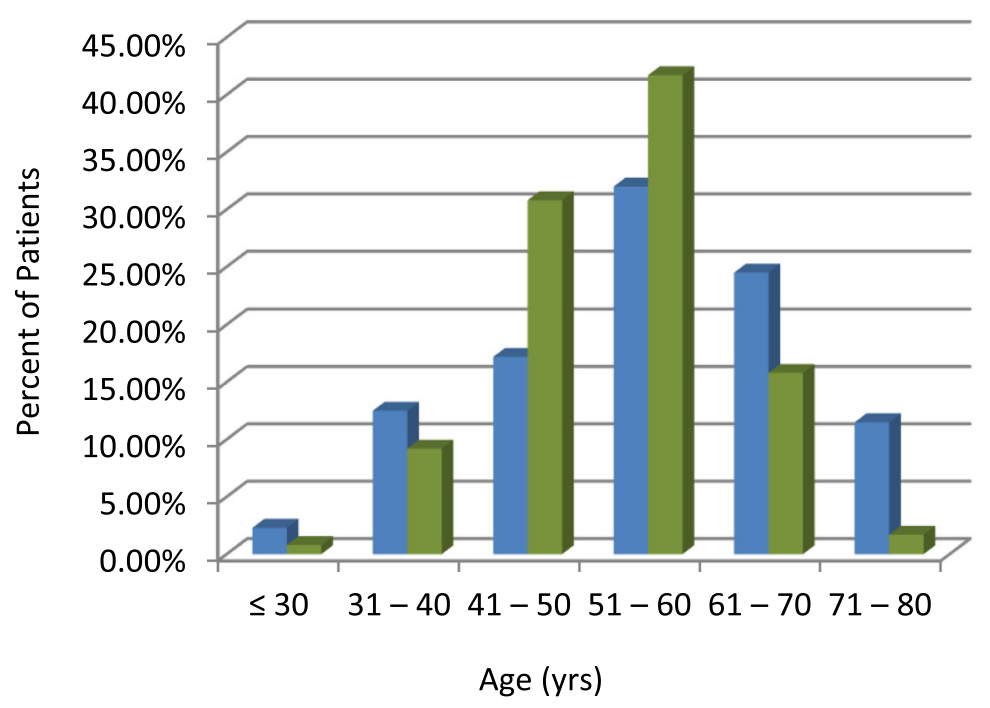

- Low Risk

High Risk

In a study by Endeshaw and colleagues the mean BP values among older adults with sleep-disordered breathing were $133 \pm 16$ and $71 \pm 8 \mathrm{mmHg}$ for systolic and diastolic BP, respectively $(p<0.001)$ (Endeshaw et al. 2009). In our study, the average systolic and diastolic BP was $133.52 \pm 17.503$ and $84.37 \pm 7.425 \mathrm{mmHg}$ (Fig. 4).

In our study, OSA was found to be strongly associated with resistant hypertension. Though our sample size was not large enough to justify a meaningful conclusion on this, another case-control study by Gonçalves et al. reported that OSA is a strong independent risk factor for resistant hypertension (Gonçalves et al. 2007). This study represents an advanced approach in the understanding of the risk factors of hypertension and gives an insight into the prevalence of high-risk of OSA in patients with hypertension. The Berlin Questionnaire, used in our study, is a validated method that has been used widely to identify individuals who are at risk for OSA (Gus et al. 2008). Our assessment of excessive daytime sleepiness was based on the ESS score, which is a well-tested international tool for the evaluation of daytime sleepiness (Boyes et al. 2017). With the increasing problem of hypertension, the impact of undetected or under-diagnosed OSA as a healthcare burden cannot be undermined. Therefore, this study can help reduce $\mathrm{CV}$ outcomes and healthcare costs of a rigorous anti-hypertensive regimen by treating the underlying cause.

There are a few limitations in our study that need to be considered. Firstly, the collection of data has been from a single tertiary care hospital for a limited period

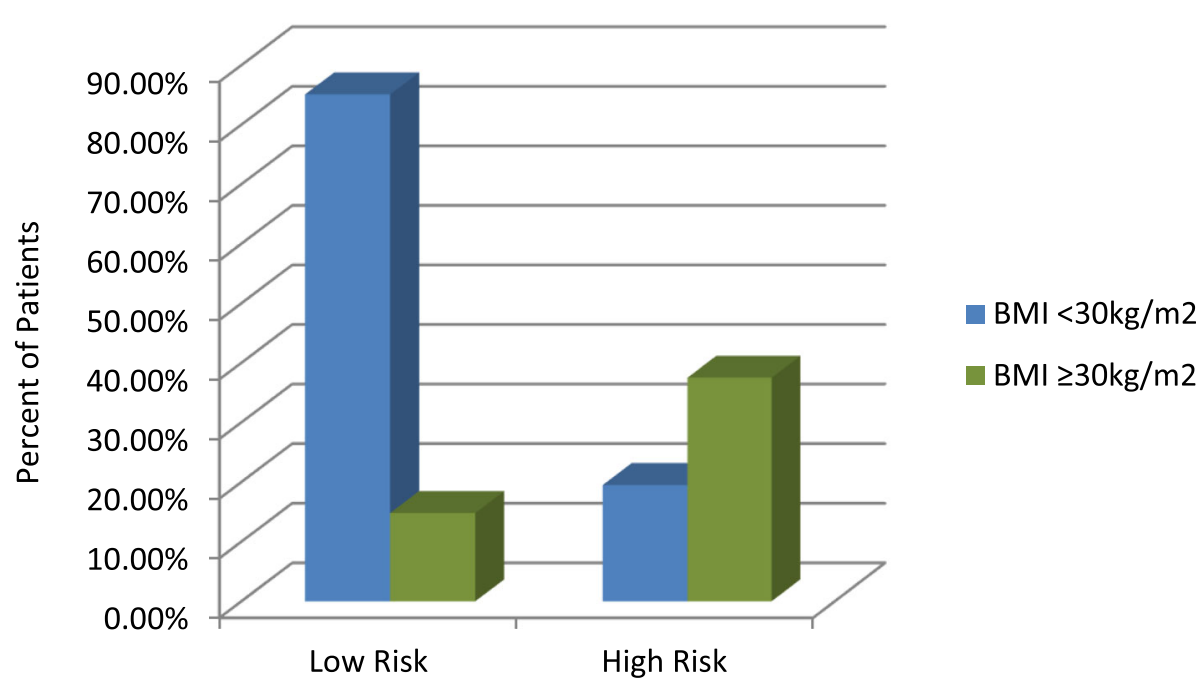

Fig. 3 Comparison between BMI and the risk of Obstructive Sleep Apnoea 


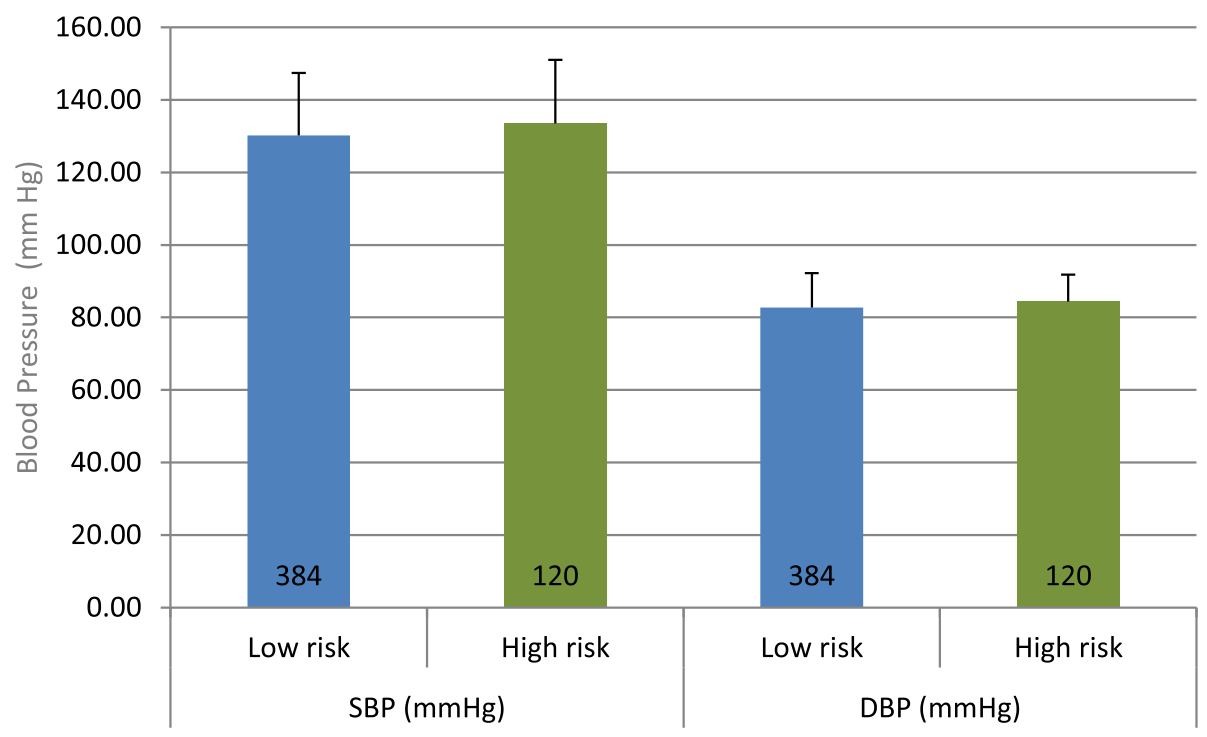

Fig. 4 Comparison of SBP and DBP in high and low risk subjects

of time yielding a small size of the patient population. Secondly, the Berlin Questionnaire was used to identify high risk for OSA instead of polysomnography which is the gold-standard test for the diagnosis of OSA in clinical settings (Pang and Terris 2006). However, it is complex, expensive, time-consuming, and is not available for the general population in India. The Berlin Questionnaire is a reliable tool and has been found to generate comparable results to that of polysomnography, yet there is a possibility of variation in the precision of results (Amra et al. 2018). We believe further studies using overnight polysomnography are warranted to exhaustively elucidate the bidirectional association between OSA and hypertension from different healthcare facilities of the state.

\section{Conclusion}

OSA is one of the most underdiagnosed and overlooked conditions in the health care system. The screening of OSA must be done in every suspected case, such as uncontrolled BP, unexplained hypertension, resistant hypertension, and obese patients. Our study concludes that nearly one in every four hypertensive patients is at high risk of OSA and most of them are obese and have a large neck circumference. Therefore, patients who feel very dizzy, fatigued and lethargic during the day should consult the physician, while the health-care personnel involved in the management of hypertensive patients should screen OSA and EDS and consider life-style modifications in patients who are at a high risk of developing OSA. The current study strengthens the acceptance of OSA as a risk factor for hypertension, in terms of essential hypertension and resistant hypertension. The results of the study suggest new and possibly modifiable variables that can be targeted in future trials focusing on hypertensive medication.

\section{Abbreviations}

BMI: Body mass index; BP: Blood pressure; ESS: Epworth sleepiness scale; HC: Hip circumference; mm Hg: Millimeters of mercury; NC: Neck circumference; OSA: Obstructive sleep apnoea; SPSS: Statistical Package for the Social Sciences; WC: Waist circumference; WHR: Waist-to-hip ratio

\section{Acknowledgments}

The authors would like to acknowledge the statistical help provided by Dr. Inam-ul-Haq, Government Medical College, Srinagar, J\&K.

\section{Authors' contributions}

GNB and MT initiated the idea and designed the study protocol. OK performed the research at the hospital under the active involvement of MT. GNB and MT supervised the overall work. GNB and OK drafted the manuscript. All authors contributed to the writing of the final manuscript and approved the final version.

\section{Funding}

This research did not receive grant of any sort from any funding agencies in the public, commercial, or not-for-profit sectors to ensure that there is no bias in collection or interpretation of data, so any role by them in the study design or data collection or analysis does not arise.

\section{Availability of data and materials}

The datasets used and/or analyzed during the current study are available from the corresponding author on reasonable request.

\section{Ethics approval and consent to participate}

Ethical approval was obtained from the Institutional Ethics Committee of Government Medical College/Shri Maharaja Hari Singh (IEC-GMC/SMHS), in accordance with Indian Council of Medical Research (ICMR) guidelines. Institutional Ethical Registration Number: 108/ETH/GMC/ICM Dated 28/10/ 2017.

A well informed written as well as verbal consent was obtained from all individual participants included in the study. 


\section{Consent for publication}

Not applicable.

\section{Competing interests}

The authors declare that they have no competing interests.

\section{Author details}

'Department of Pharmaceutical Sciences, University of Kashmir, Hazratbal, Srinagar, J\&K 190006, India. 'Department of General Medicine, Government Medical College, Karanagar, Srinagar, J\&K 190010, India.

Received: 28 July 2020 Accepted: 19 October 2020

Published online: 29 October 2020

\section{References}

Amra B, Rahmati B, Soltaninejad F, Feizi A. Screening questionnaires for obstructive sleep apnea: an updated systematic review. Oman Med J. 2018; 33(3):184-92.

Bouloukaki I, Steiropoulos P, Bonsignore M, Mcnicholas W, Hedner J, Grote L, et al. Mild obstructive sleep apnoea (OSA) and arterial hypertension in the European Sleep Apnoea Database (ESADA) cohort study. Eur Respir J. 2018; 52(suppl 62). https://erj.ersjournals.com/content/52/suppl_62/OA4964.

Boyes J, Drakatos P, Jarrold I, Smith J, Steier J. The use of an online Epworth sleepiness scale to assess excessive daytime sleepiness. Sleep Breath. 2017; 21(2):333-40

Bradley TD, Floras JS. Sleep apnea and heart failure: part l: obstructive sleep apnea. Circulation. 2003;107(12):1671-8

Calhoun DA, Jones D, Textor S, Goff DC, Murphy TP, Toto RD, et al. Resistant hypertension: diagnosis, evaluation, and treatment: a scientific statement from the American Heart Association Professional Education Committee of the Council for High Blood Pressure Research. Hypertension. 2008;51(6):1403-19.

Chobanian AV, Bakris GL, Black HR, Cushman WC, Green LA, Izzo JL, et al. Seventh report of the Joint National Committee on prevention, detection, evaluation, and treatment of high blood pressure. Hypertension. 2003;42(6):1206-52.

Deng X, Gu W, Li Y, Liu M, Li Y, Gao X. Age-group-specific associations between the severity of obstructive sleep apnea and relevant risk factors in male and female patients. PLoS One. 2014:9(9):e107380.

Endeshaw YW, White WB, Kutner M, Ouslander JG, Bliwise DL. Sleep-disordered breathing and 24-hour blood pressure pattern among older adults. J Gerontol A Biol Sci Med Sci. 2009;64(2):280-5.

Fink B. Neck circumference: its usage in medicine and biology. In: Preedy VR, editor. Handbook of anthropometry. New York: Springer; 2012. p. 665

Global Health Observatory (GHO) data. Raised bloood pressure. 2018. [6 screens]. Available from: http://www.who.int/gho/ncd/risk_factors/blood_pressure_ prevalence_text/en/. Cited 2018 Feb 23.

Gonçalves SC, Martinez D, Gus M, de Abreu-Silva EO, Bertoluci C, Dutra I, et al. Obstructive sleep apnea and resistant hypertension: a case-control study. Chest. 2007:132(6):1858-62.

Guilleminault C, Abad VC. Obstructive sleep apnea. Curr Treat Options Neurol. 2004;6(4):309-17.

Gus M, Gonçalves SC, Martinez D, de Abreu Silva EO, Moreira LB, Fuchs SC, et al. Risk for obstructive sleep apnea by Berlin questionnaire, but not daytime sleepiness, is associated with resistant hypertension: a case-control study. Am J Hypertens. 2008;21(7):832-5.

Hiestand DM, Britz P, Goldman M, Phillips B. Prevalence of symptoms and risk of sleep apnea in the US population. Chest. 2006;130(3):780-6.

International Diabetes Federation (IDF). The IDF consensus worldwide definition of the metabolic syndrome. Available from: https://www.pitt.edu/ super1/ Metabolic/IDF1.pdf. Cited 2019 Feb 12

Ip M, Chung KF, Chan KN, Lam SP, Lee K. Previously unrecognized obstructive sleep apnea in Chinese subjects with essential hypertension. Lung. 1999; 117(6):391-400

James PA, Oparil S, Carter BL, Cushman WC, Dennison-Himmelfarb C, Handler J, et al. 2014 evidence-based guideline for the management of high blood pressure in adults: report from the panel members appointed to the Eighth Joint National Committee (JNC). JAMA. 2014;311(5):507-20.

Johns MW. A new method for measuring daytime sleepiness: the Epworth sleepiness scale. Sleep. 1991;14(6):540-5.

Kang HH, Kang JY, Ha JH, Lee J, Kim SK. The associations between anthropometric indices and obstructive sleep apnea in a Korean population; 2014. p. 1-12. https://doi.org/10.1371/journal.pone.0114463.
Kearney PM, Whelton M, Reynolds K, Muntner P, Whelton PK, He J. Global burden of hypertension: analysis of worldwide data. Lancet. 2005;365(9455):217-23.

Lavie P, Herer P, Hoffstein V. Obstructive sleep apnoea syndrome as a risk factor for hypertension: population study. BMJ. 2000;320(7233):479-82.

Lawes C, Vander Hoorn S, Rodgers A, International Society of Hypertension. Global burden of blood pressure related disease, 2001. Lancet. 2008; 371(9623):1531-8.

Leung RT, Bradley DT. Sleep apnea and cardiovascular disease. Am J Respir Crit Care Med. 2001;164(12):2147-65.

Marin J, Agusti A, Villar I, Forner M, Nieto D, Carrizo SJ, et al. Association between treated and untreated obstructive sleep apnea and risk of hypertension. JAMA. 2012;307(2):2169-76.

Min HJ, Cho YJ, Kim CH, Kim DH, Kim HY, Choi Jl, et al. Clinical features of obstructive sleep apnea that determine its high prevalence in resistant hypertension. Yonsei Mrd J. 2015:56(5):1258-65.

Mubarik A, Burney W, Khan SA, Qasim M, Basit M, Hassan SM. Prevalence of comorbididites in obstructive sleep apnea population waiting for bariatric surgery. J Gen Emerg Med. 2017;2(6):32.

Muntner P, Shimbo D, Carey RM, Charleston JB, Gaillard T, Misra S, et al. Measurement of blood pressure in humans: a scientific statement from the American Heart Association. Hypertension. 2019;73(5):e35-66.

Muxfeldt ES, Margallo VS, Guimarães GM, Salles GF. Prevalence and associated factors of obstructive sleep apnea in patients with resistant hypertension. Am J Hypertens. 2014;27(8):1069-78.

Netzer NC, Stoohs RA, Netzer CM, Clark K, Strohl KP. Using the Berlin questionnaire to identify patients at risk for the sleep apnea syndrome. Ann Intern Med. 1999;131(7):485-91.

Ngahane BHM, Nganda MM, Dzudie A, Luma H, Kamdem F, Ngote HR, et al. Prevalence and determinants of excessive daytime sleepiness in hypertensive patients: a cross-sectional study in Douala, Cameroon. BMJ Open. 2015;5(7): e008339.

Pang KP, Terris DJ. Screening for obstructive sleep apnea: an evidence-based analysis. Am J Otolaryngol. 2006;27(2):112-8.

Park JG, Ramar K, Olson EJ. Updates on definition, consequences, and management of obstructive sleep apnea. Mayo Clin Proc. 2011;86(6): 549-54.

Pensuksan WC, Chen X, Lohsoonthorn V, Lertmaharir S, Gelave B, Williams MA. High risk for obstructive sleep apnea in relation to hypertension among southeast Asian young adults: role of obesity as an effect modifier. Am J Hypertens. 2014;27(2):229-36.

Peppard PE, Terry Y, Jodi HB, Mari P, Hagen EW, Hla KM. Increased prevalence of sleep-disordered breathing in adults. Am J Epidemiol. 2013;177(9):1006-14.

Peppard PE, Young T, Palta M, Skatrud J. Prospective study of the association between sleep disordered breathing and hypertension. N Engl J Med. 2000; 342(19):1378-84

Pien GW, Rosen IM, Fields BG. Fishman's pulmonary diseases and disorders. Sleep apnea syndromes: central and obstructive sleep apnea. 5th ed. New York: McGraw-Hill Education; 2015.

Reddy EV, Kadhiravan T, Mishra HK, Sreenivas V, Handa KK, Sinha S, et al. Prevalence and risk factors of obstructive sleep apnea among middle-aged urban Indians: a community-based study. Sleep Med. 2009;10(8):913-8.

Senaratna CV, Perret JL, Lodge CJ, Lowe AJ, Campbell BE, Matheson MC, et al. Prevalence of obstructive sleep apnea in the general population: a systematic review. Sleep Med Rev. 2017;34:70-81.

Sharma SK, Ahluwalia G. Epidemiology of adult obstructive sleep apnoea syndrome in India. Indian J Med Res. 2010;131:171-5.

Sharma SK, Kumpawat S, Banga A, Goel A. Prevalence and risk factors of obstructive sleep apnea syndrome in a population of Delhi, India. Chest. 2006;130(1):149-56

Shirani G, Morovati SP, Shamshiri AR, Nouri M, Givi NE, Farhadi M. Prevalence of cardiovascular disorders in Iranian patients suffering from obstructive sleep apnea. J Dent (Tehran). 2016:13(3):151-6.

Tan A, Yin JD, Tan LW, van Dam RM, Cheung YY, Lee CH. Using the Berlin questionnaire to predict obstructive sleep apnea in the general population. $J$ Clin Sleep Med. 2017;13(3):427-32

Udwadia ZF, Doshi AV, Lonkar SG, Singh Cl. Prevalence of sleep-disordered breathing and sleep apnea in middle-aged urban Indian men. Am J Respir Crit Care Med. 2004;169(2):168-73.

Wali S, Abalkhail O, Krayem A. Prevalence and risk factors of obstructive sleep apnea syndrome in a Saudi Arabian population. Ann Thorac Med. 2017:12(2): 88-94. 
Williams B, Mancia G, Spiering W, Rosei EA, Azizi M, Burnier M, et al. 2018 ESC/

ESH Guidelines for the management of arterial hypertension. The Task Force for the Management of Arterial Hypertension of the European Society of Cardiology (ESC) and the European Society of Hypertension (ESH). Eur Heart J. 2018;39:3021-104.

World Health Organization. Global database on body mass index. 2016. Available from: http://www.assessmentpsychology.com/icbmi.htm. Cited 2019 Jan 28.

\section{Publisher's Note}

Springer Nature remains neutral with regard to jurisdictional claims in published maps and institutional affiliations.

Ready to submit your research? Choose BMC and benefit from:

- fast, convenient online submission

- thorough peer review by experienced researchers in your field

- rapid publication on acceptance

- support for research data, including large and complex data types

- gold Open Access which fosters wider collaboration and increased citations

- maximum visibility for your research: over $100 \mathrm{M}$ website views per year

At BMC, research is always in progress.

Learn more biomedcentral.com/submissions 